\title{
How Do Gender, Age and Travel Time Impact on the Need for Social Support of Patients to Have Access to Cancer Treatment?
}

\author{
Ph. Groux ${ }^{1}$, S. Anchisi ${ }^{2} \&$ Th. Szucs ${ }^{3}$ \\ ${ }^{1}$ Kundengerecht.ch GmbH, Alpenstrasse 22, 4950 Huttwil, Switzerland \\ ${ }^{2}$ Département de médecine interne et gériatrie, service d'oncologie, CHVR-hôpital du Valais, Avenue de \\ Grand-Champsec 80, 1951 Sion, Switzerland \\ ${ }^{3}$ European Center of Pharmaceutical Medicine, University of Basel, Klingelbergstrasse 61, 4056 Basel, \\ Switzerland
}

Correspondence: Dr. Philippe Groux, MPH, kundengerecht.ch GmbH, Alpenstrasse 22, 4950 Huttwil, Switzerland. Tel: 41-79-203-1411. E-mail: philippe.groux@kundengerecht.ch

Received: June 26, 2014 Accepted: August 21, 2014 Online Published: September 25, 2014

doi:10.5539/cco.v3n2p27 URL: http://dx.doi.org/10.5539/cco.v3n2p27

\begin{abstract}
Purpose: Disparities in cancer treatment for geographical and socioeconomic reasons have been demonstrated in several countries. In Valais, a canton in Switzerland, to travel to one of the oncology wards can be time consuming, cost intensive and make support by relatives or external persons and institutions necessary.

Method: We investigated which kind of support cancer patients in Valais need today to make a treatment possible, quantified it and identified subgroups with particular needs. All patients who came in February 2012 for a consultation or an ambulant therapy to one of the four centres of the "Département Valaisan d'Oncologie" or the unique private practice in the region were asked to answer to a questionnaire. Results were summarised and analysed.

Results: $84 \%$ of the patients need support. $40 \%$ of the patients need two or more kinds of support. Kind and quantity of support depend on gender, age and distance. Cancer patients in Valais need support to make their treatments possible. Some subgroups have a complex pattern of support and need specific assistance as younger women or elderly patients.

Conclusions: We demonstrate that cancer patients in Valais need social support to handle their treatment days and that their out of the pocket travel expenses increase rapidly with distance. The pattern of support needed varies according to patient characteristics as gender, age and distance to treatment centre.
\end{abstract}

Keywords: cancer, families, older patients, social support

\section{Introduction}

Disparities in cancer treatments have been shown in many countries (Byers et al., 2008; Dejardin et al., 2005; Eaker et al., 2009; Gori et al., 2010; Halmin et al., 2008; Haynes, Pearce \& Barnett, 2008; Jones et al., 2008; Lejeune et al., 2010; Maddison, Asad, \& Urquhart, 2011; Olver, Marine, \& Grogan, 2011; Rosato et al., 2009; Siminoff \& Ross, 2005). Influence of socioeconomic determinants on cancer treatment has been demonstrated (Mackenbach et al., 2008; Merletti, Galassi, \& Spadea, 2011; Morimoto, Coalson, Mowat, \& O’Malley, 2010; Senior, 2009). Having to travel for treatment cause many practical, emotional and financial problems to patients and burden them with additional worry concerning family and work commitments (Butow et al., 2012). Recent publications highlighted as well travel-related burden for cancer patients (Zucca, Boyes, Newling, Hall, \& Girgis, 2011), and financial and social impacts for support persons of cancer survivors (Carey et al., 2012) as impact of age and distance on the willingness of cancer patients to travel more or further away for a slightly more efficient therapy (Groux, Anchisi, \& Szucs, 2014).

The Swiss health system is based on principles of free demand and supply as well as regulated competition (Busato \& Künzi, 2008) with a fee-for-service system for the reimbursement. As travel costs are not reimbursed they can increase the travel-related burden for patients living in remote areas.

Valais is a Swiss alpine canton at the south-western border of the country and consists in the main Rhone river 
valley and lateral valleys of several feeder rivers. Three quarters of the population live in the French speaking part, one quarter in the eastern German speaking part. The Département Valaisan d'Oncologie (DVO) offers treatments in four different regional hospitals (Brig, Martigny, Sion, Sierre) and runs a radio-oncology service in Sion. Chemotherapies are also administered by the Hôpital du Chablais-Riviera in Monthey and a private practice in Sierre. A former study disclosed transport issues as a major obstacle to cancer treatment for elderly patients (S. Anchisi \& A. Anchisi, 2008). These results have been confirmed by a recent study which also demonstrated that cancer patients in Valais outline this issue when discussing cancer treatment with their general practitioner and medical oncologist (Groux \& Szucs, 2013). Free transport services for patients who need help are offered by the local cancer league: volunteers drive the patients of the French speaking part in their private car and for radio-oncology patients of the German speaking part a daily bus starting in Brig and stopping at each railway station drives the patients to Sion, where a special time slot is reserved for them.

We investigated the need for social support of all patients coming in February 2012 for consultation or ambulant therapy to one of the four centres of the DVO or to the private practice. The aim was to characterize and quantify the kind of support the patients required and to identify groups of patients with particular support needs.

Approval for the study was obtained from the medical-ethical commission of the canton of Valais.

\section{Methods}

All patients coming in February 2012 for consultation or ambulant treatment to one of the four centres of the DVO or to the private practice were asked to answer a survey. Patients who came for the first time were excluded. Patients were asked to fill out the questionnaire at least once per centre. If a patient came up in two different centres he was asked to answer in both centres. The questionnaire covered items as gender, date of birth, living place, kind of cancer, kind of treatment and questions covering different aspects of the travel: how the patient travelled to the centre, how long the travel lasted and which kind of support was necessary to travel and who provided this support.

Five forms of social support were screened:

(1) whether patients came alone or accompanied;

(2) whether somebody took care of children, pets etc. during the absence of the patient;

(3) whether they needed external help at home during their absence;

(4) which means of transport were used; and

(5) whether they came directly from their home and if not whether they spent the night abroad to stay closer to the treatment centre.

The survey was pre-tested for comprehension with a small group of twelve persons representing age groups, gender, languages and educational level as expected among patients of the survey. The wording was slightly adapted after pre-test by simplifying some questions. The relevant questions of the questionnaires are described in Table 1.

The data were summarized and analyzed using Microsoft Excel and EpiData Analysis (Epidata Association, Odense, Denmark). Patients who answered they came alone and named an accompanying person in the sub question were considered with contradictory answers (28) and excluded as well as patients not living in Valais (2) or not having cancer (23). Patients with haematological problems without cancer are followed in the same wards. If a patient answered twice to the questionnaire at the same site only the first questionnaire was considered.

Table 1. Excerpts of the questionnaire with all questions relevant for this publication

\begin{tabular}{|c|c|}
\hline Question & Possible answers \\
\hline \multirow[t]{7}{*}{ 1) Did you already answer once to this questionnaire? } & Yes, in \\
\hline & Brig \\
\hline & Martigny \\
\hline & Sion \\
\hline & Sierre \\
\hline & Private practice in Sierre \\
\hline & No \\
\hline
\end{tabular}


2) My gender is

3) My birthday is (Day/Month/Year)

4) I live in

5) I live alone

6) I have the following cancer diagnosis

7) Which cancer therapy do you receive today?

8) How did you travel today to the ward?

9) How long did your journey last?

10) Did you start your journey at home?

11) Did you sleep abroad to be closer to the treatment centre?

12) Did you come alone or accompanied?

13) Who takes care of your family, children, and animals during your absence?

14) Do you need external help during your absence? female

male

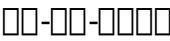

Postal code Location

Yes

No

Prostate

Breast

Colon

Lung

Skin

Other

I don't know

I don't have cancer

Chemotherapy

Radiotherapy

Chemo- and Radiotherapy

Other

No cancer therapy

Private car

Public transportation

Taxi

Transport services of the cancer league *

Bus of radio-oncology *

Walk

Other

Less than 15 minutes

Less than 30 minutes

Less than 1 hour

More than 1 hour

Yes

No

Yes *

No

Alone

Accompanied *

My marriage/life partner *

My children *

My parents *

Other members of the family *

Friends *

Neighbour *

Volunteer *

Nobody

I don't need help

Yes *

No

Note. Question 12 had a sub question "if accompanied, by whom?" with the same answers as question 13 but the last one (I don't need help). * Kinds of support considered in this study. 
Table 2. Patient characteristics

\begin{tabular}{|c|c|}
\hline Characteristics & Result \\
\hline \multicolumn{2}{|l|}{ Gender } \\
\hline Women & $167(56 \%)$ \\
\hline Men & $131(44 \%)$ \\
\hline Median age & 64 years (95\% CI: $63-65)$ \\
\hline Women & 60 years ( $95 \%$ CI: 58 - 62) \\
\hline Men & 66 years (95\% CI: $64-68)$ \\
\hline Age range & 19 to 87 years old \\
\hline \multicolumn{2}{|l|}{ Language } \\
\hline French & $199(67 \%)$ \\
\hline German & $99(33 \%)$ \\
\hline \multicolumn{2}{|l|}{ Type of cancer in women } \\
\hline Breast & $84(50 \%)$ \\
\hline Lung & $17(10 \%)$ \\
\hline Colorectal & $13(8 \%)$ \\
\hline Others & $46(28 \%)$ \\
\hline Not answered & $7(4 \%)$ \\
\hline \multicolumn{2}{|l|}{ Type of cancer in men } \\
\hline Colorectal & $23(18 \%)$ \\
\hline Prostate & $22(17 \%)$ \\
\hline Lung & $12(9 \%)$ \\
\hline Others & $62(47 \%)$ \\
\hline Not answered & $6(5 \%)$ \\
\hline \multicolumn{2}{|l|}{ Distance to treatment centre } \\
\hline below 15 minutes & $122(41 \%)$ \\
\hline between 15 and 30 minutes & $100(34 \%)$ \\
\hline between 30 and 60 minutes & $55(18 \%)$ \\
\hline more than 60 minutes & $21(7 \%)$ \\
\hline \multicolumn{2}{|l|}{ Reason of the visit } \\
\hline Chemotherapy & $152(51 \%)$ \\
\hline Radiotherapy & $17(6 \%)$ \\
\hline Radiotherapy plus chemotherapy & $15(5 \%)$ \\
\hline Other treatment e.g. for side-effects & $49(16 \%)$ \\
\hline No treatment e.g. consultation only & $47(16 \%)$ \\
\hline Not answered & $18(6 \%)$ \\
\hline
\end{tabular}

298 patients answered all requested questions.

\section{Results}

629 questionnaires were handed out from which 619 were collected. 408 different patients participated to the survey and 298 different patients answered all requested questions for this publication (73\% of all participating patients). Patient characteristics are summarized in Table 2.

251 patients (84\%) needed at least one of the described kinds of support (seeTable 1), 134 (45\%) needed one, 82 
(27\%) two, $33(11 \%)$ three and $2(1 \%)$ four kinds of support. 186 patients (62\%) came accompanied, $154(52 \%)$ required help at home during the treatment, $25(8 \%)$ needed external help at home, $18(6 \%)$ came with an offered transport service. Only $3(1 \%)$ stayed closer to the hospital to reduce the distance. Among the 117 patients who requested at least two kinds of support, 94 times it was the combination "be accompanied" and "need for help at home during the absence".

The four distance groups (see Table 2) were not homogenous as well for the gender ratio (65\% women in group $1,57 \%$ group $2,33 \%$ group 3, 62\% group 4) as for the median age (60 years / 64 years / 66 years / 65 years). To allow comparisons between distance group data were standardized for age and gender.

Women tended to call more for support than men (Figure 1). The difference was not statistically significant for isolated items, but the combination of the need for an accompanying person with somebody helping at home was statistically significant with an OR of 2.1 (95\% CI 1.3-3.5).

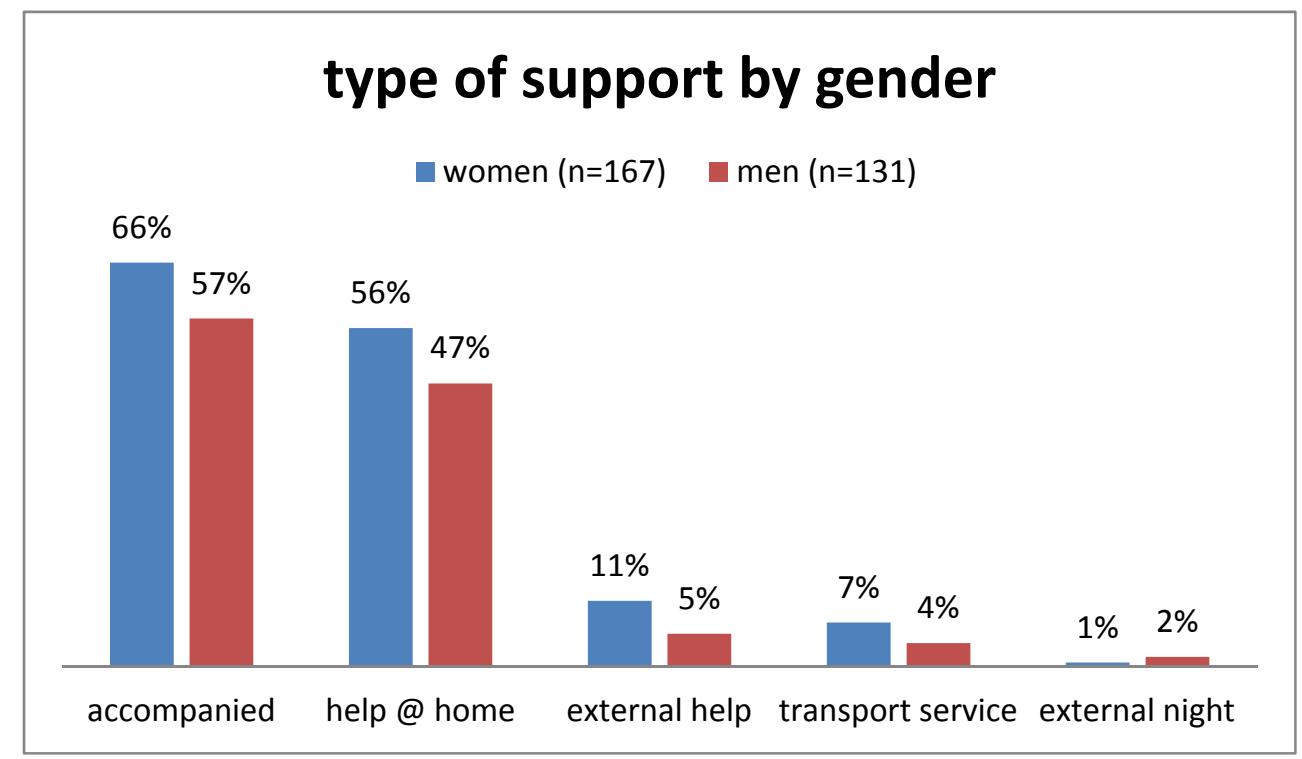

Figure 1. Women tend to claim more for support than men

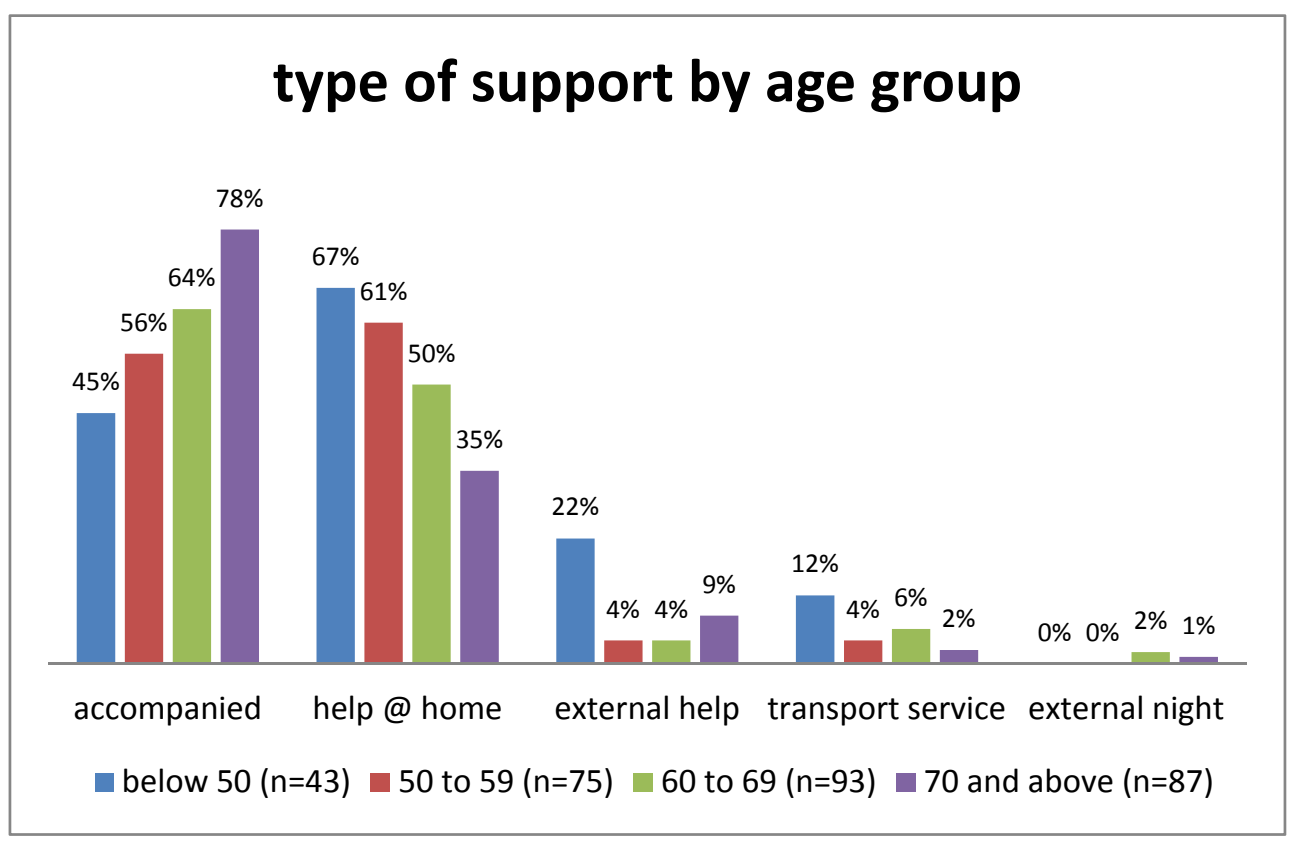

Figure 2. The kind of support claimed varies by age. An accompanying person becomes more important with increasing age; meanwhile help at home becomes less important 
Age of the patients influences the kind of support they need (figure 2). $45 \%$ of the patients below 50 years came alone to the treatment but $67 \%$ needed help at home. On the other hand $78 \%$ of elderly patients ( 70 years old or above) came accompanied to the treatment but only $35 \%$ needed help at home. The percentage of accompanied patients increases from age group to age group and the need for help at home declines from age group to age group. Help at home, external assistance and transport service are particularly required by the youngest patients (below 50 years). The differences were statistically significant with an OR of 3.7 (95\% CI $1.8-7.9$ ) for help at home, 5.9 (95\% CI 2.5 - 14.2) for external help and 3.6 (95\% CI 1.3 - 10.3) for transport services.

Distance from the place of residence to the oncology centre impacts on the type of support (figure 3). The four distance groups (see table 2) were not homogenous as well for the gender ratio as for the median age. To allow comparisons between distance group data were standardized for age and gender. Below 15 minutes a majority of patients (54\%) travel alone, patients with a distance greater than 15 minutes travel mainly accompanied (79\%), OR of 6.3 (95\% CI 3.6-11.0). Above 60 minutes transport services gained in importance (33\% of the patients used transport services and $40 \%$ came with an accompanying person). The percentage of patients requiring help at home decreases rapidly with growing distance except for the longest distance. From distance group 1 to distance group 3 the need drops from $67 \%$ to $35 \%$ (OR $3.5,95 \%$ CI $1.8-6.9$ ). No statistically significant differences are observed as well for the need for external help as for external overnight.

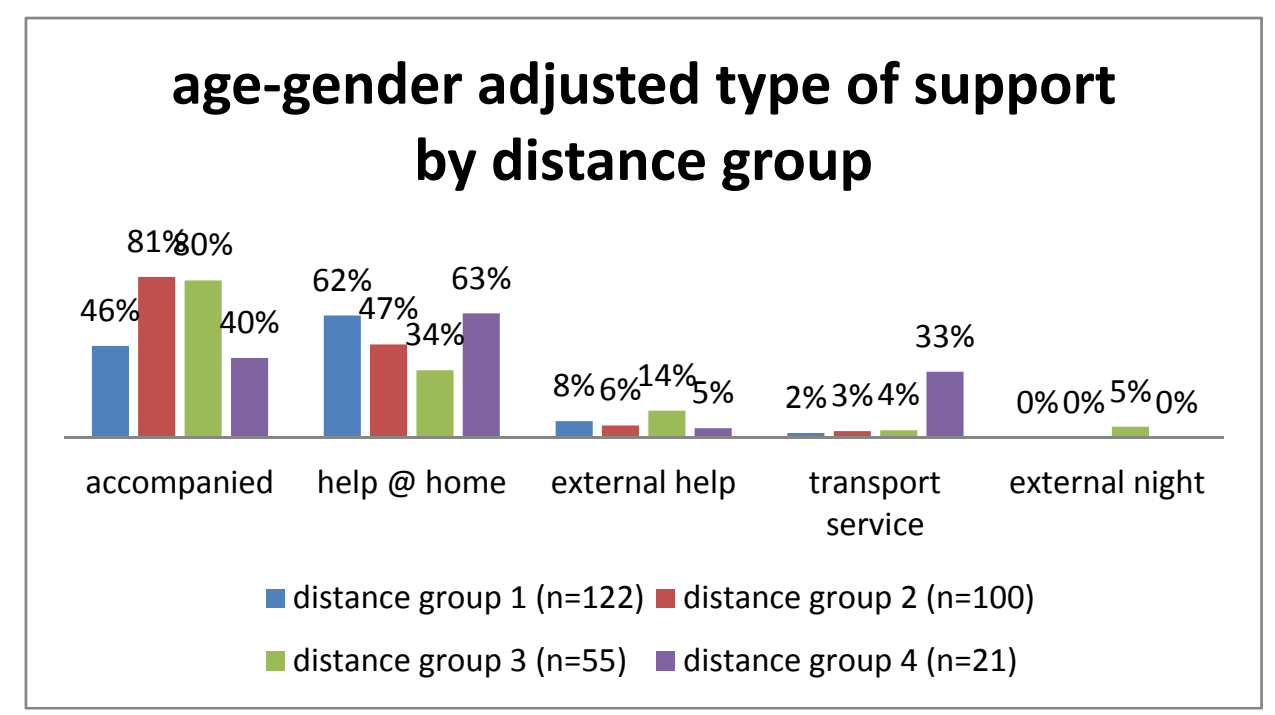

Figure 3. Travel time influences the kind of support claimed. Three distinguished groups exist: those with less than 15 minutes to travel (distance group 1), those between 15 and 60 minutes (distance groups 2 and 3 ) and those above 60 minutes (distance group 4)

\section{Discussion}

To travel for cancer treatment causes many practical, emotional and financial problems to patients and caregivers, burdens them with additional worry concerning family and work commitments and has a financial and social impact for support persons of cancer survivors and the patients themselves. A journey for a cancer treatment last much longer than the treatment itself. The more persons are required to make the journey possible the higher social impact for patients and support persons is.

We investigated how extensively cancer patients in Valais call for social support to have access to their treatment, focusing on the "travel problems". We come to the conclusion, that they very frequently need support for the journey and during their absence from home. In fact, 8 out of 10 patients need at least one kind of support investigated (accompanying person for the travel, help at home, external help, free transport service and overnight closer to the treatment centre) to get their treatment. About $40 \%$ of patients need even two or more kinds of support.

The most frequent need (62\%) is to come accompanied. This doesn't necessarily mean that patients are unable to come alone. We can speculate that insecurity in driving or the need to have moral support are other reasons to come accompanied to the ward. Somebody helping at home during the journey is nearly as frequent with $52 \%$ of 
the patients having this form of support whereas external help, free transport services or sleeping closer to the centre concern only a minority of patients.

Which kind of support the patients require depends on age, gender and distance to the centre. Women tend to require more support than men. Although difference is not statistically significant for single item she need to have at the same time an accompanying person and somebody helping at home during the absence for treatment is statistically more frequent for women. This is potentially linked to the pattern of cancer incidence with age, particularly breast cancer, a cancer disease with a younger patient population, and to the typical socio-family roles with women in charge of children education and household.

With increasing age, most patients need help for the travel. Only 1 out of 5 elderly patients comes alone. Need for help at home on the contrary decreases with age.

When the travelling distance is greater than 15 minutes, 4 of 5 patients don't come alone, independently of age and gender. We assume that this is linked to the question whether the patient feels strong enough to travel alone.

Patients living more than an hour from the treatment centre are a small minority (7\%). In the French speaking travel part such a long journey is linked to radiotherapy, in the German speaking part journeys of more than an hour are also possible for chemotherapy patients. Their pattern of support differs from the pattern of the rest of the population. One third of them chose the free transport service offered by the cancer league. As travel expenses are not covered by the health care insurance, travel costs are high for these patients. For radiotherapy they have to travel every working day for 2 to 6 weeks. Whether these patients chose free transport to avoid having to pay high travel expenses cannot be answered with our data.

Two other groups of patients need specific support: patients below 50 years of age and those 70 years and above. With $16 \%$ and $27 \%$ respectively they are more numerous than patients living far away from a centre. In both groups many persons, mainly relatives, are involved to handle the treatment days. If the patient came alone the life partner helped at home in 4 of 10 cases, as well for the patients in distance group 4 travelling with a transport service. One reason why more patients travel alone in distance group 1 and more patients use travel service in distance group 4 could potentially be that these patients had to choose other solutions to travel because their life partner had to stay at home and take care of children, animals etc.

Patients younger than 50 years as the elderly ones require more help at home. This is probably linked to the family structure evolving with age. All patients requiring external help were women except one and almost one young woman out of four asked for external help, which is distinctly more than for other age groups. They all lived in a multi-person household except one, had almost always additionally a relative or the life partner taking care at home for children, animals etc. and a majority of these patients came accompanied, which is atypical for this age group. The accompanying person was always but in one case a relative or the life partner. This complex pattern of need for support is quite a burden for the family.

If a patient can't travel alone or if a patient needs somebody at home to bridge its absence e.g. to take care of children we can speculate that this creates a moral commitment to succeed in treatment, whatever success will mean in the patient's specific situation. To mobilize relatives, friends and neighbours to make a cancer treatment possible increases the burden of the treatment itself and can cause wearing worry.

The study methodology has several limitations, particularly the voluntariness to participate to the survey and to answer to the specific questions of interest for this investigation. Socioeconomic factors as education level, income class, immigration background or size of the household were not collected, bias is therefore possible. For example the decline of percentage of patients requiring help at home with growing distance could be biased by other factors, e.g. the type of cancer. We renounced to a multivariate model as our questionnaire didn't contain all these relevant factors, accepting the limitation of a univariate logistic regression. The survey was done during winter where snow causes additional difficulties to travel.

\section{Conclusion}

We demonstrate that cancer patients in Valais need social support to handle their treatment days. Pattern of support needed varies according to patient characteristics as gender, age and distance to treatment centre. Most of this support is given by the family of the patient. Support given by the cancer league to solve transport problems is not negligible. Needs are particularly high for some subgroups. Further analysis of our data is ongoing and will be published separately. Our observational study allows generating hypothesis to explore reasons for the described extended extensive needs. 


\section{Acknowledgements}

The authors would like to gratefully acknowledge the staff of the five involved centres for their active role by encouraging patients to fill out the questionnaire. This study has been supported by an unrestricted grant from Pierre Fabre Oncology Switzerland.

\section{References}

Anchisi, S., \& Anchisi, A. (2008). Vivre la chimiothérapie au quotidien: un processus qui révèle l'âge. Bull Cancer; 95(suppl. FMC): F44-50.

Busato, A., \& Künzi, B. (2008). Primary care physician supply and other key determinants of health care utilization: the case of Switzerland. BMC Health Services Research, 8(8). http://dx.doi.org/10.1186/1472-6963-8-8

Butow, P. N., Philipps, F., Schweder, J., White, K., Underhill, C., \& Goldstein, D. on behalf of the Clinical Oncological Society of Australia. (2012). Psychosocial well-being and supportive care needs of patients living in urban and rural/regional areas: a systematic review. Support Care Cancer, 20, 1-22. http://dx.doi.org/10.1007/s00520-011-1270-1

Byers, T. E., Wolf, H. J., Bauer, K. R., Bolick-Aldrich, S., Chen, V. W., Finch, J. L., ... Yin, X. (2008). The impact of socioeconomic status on survival after cancer in the United States: findings from the National Program of Cancer Registries Patterns of Care Study. Cancer, 113(3), 582-591. http://dx.doi.org/10.1002/cncr.23567

Carey, M., Paul, C., Cameron, E., Lynagh, M., Hall, A., \& Tzelepis, F. (2012). Financial and social impact of supporting a haematological cancer survivor. Eur $J$ Cancer Care, 21, 169-176. http://dx.doi.org/10.1111/j.1365-2354.2011.01302.x

Dejardin, O., Bouvier, A. M., Herbert, C., Velten, M., Buemi, A., Delafosse, P., ... Launoy, G. (2005). Social and geographic disparities in access to reference care site for patients with colorectal cancer in France. $\mathrm{Br} J$ Cancer, 92, 1842-1845. http://dx.doi.org/10.1038/sj.bjc.6602571

Eaker, S., Halmina, M., Bellocco, R., Bergkvist, L., Ahlgren, J., Holmberg, L. \& Lambe, M. (2009). Uppsala/Orebro Breast Cancer Group. Social differences in breast cancer survival in relation to patient management within a National Health Care System (Sweden). Int J Cancer, 124(1), 180-187. http://dx.doi.org/10.1002/ijc.23875

Gori, S., Di Maio, M., Pinto, C., Alabiso, O., Baldani, E., Beretta, G. D., ... Venturini, M. (2010). AIOM Working Group Interaction with Regional Sections (2007-2009). Differences in the availability of new anti-cancer drugs for Italian patients treated in different regions. Results of analysis conducted by the Italian Society Of Medical Oncology (AIOM). Tumori, 96(6), 1010-1015.

Groux, P., \& Szucs, T. (2013). Geographic disparities in access to cancer care: do patients in outlying areas talk about their access problems to their general practitioners and medical oncologists and how does that impact on the choice of chemotherapy? Eur J Cancer Care, 22(6), 746-753. http://dx.doi.org/10.1111/ecc.12096

Groux, P., Anchisi, S., \& Szucs, T. (2014). Are cancer patients willing to travel more or further away for a slightly more efficient therapy? Cancer and Clinical Oncology, 3(1), 36-42. http://dx.doi.org/10.5539/cco.v3n1p36

Halmin, M., Bellocco, R., Lagerlund, M., Karlsson, P., Tejler, G., \& Lambe, M. (2008). Long-term inequalities in breast cancer survival-a ten year follow-up study of patients managed within a National Health Care System (Sweden). Acta Oncol, 47(2), 216-224. http://dx.doi.org/10.1080/02841860701769768

Haynes, R., Pearce, J., \& Barnett, R. (2008). Cancer survival in New Zealand: ethnic, social and geographical inequalities. Soc Sci Med, 67(6), 928-937. http://dx.doi.org/10.1016/j.socscimed.2008.05.005

Jones, A. P., Haynes, R., Sauerzapf, V., Crawford, S. M., Zao, H., \& Forman, D. (2008). Travel time to hospital and treatment for breast, colon, rectum, lung, ovary and prostate cancer. Eur J Cancer, 44(7), 992-999. http://dx.doi.org/10.1016/j.ejca.2008.02.001

Lejeune, C., Sassi, F., Ellis, L., Godward, S., Mak, V., Day, M., \& Rachet, B. (2010). Socio-economic disparities in access to treatment and their impact on colorectal cancer survival. International Journal of Epidemiology, 39, 710-717. http://dx.doi.org/10.1093/ije/dyq048

Mackenbach, J. P., Stirbu, I., Roskam, A. J. R., Schaap, M. M., Menvielle, G., Leinsalu, M., ... for the European Union Working Group on Socioeconomic Inequalities in Health (2008). Socioeconomic Inequalities in 
Health in 22 countries. $N$ Engl J Med, 358, 2468-2481. http://dx.doi.org/10.1056/NEJMsa0707519

Maddison, A. R., Asada, Y., \& Urquhart, R. (2011). Inequity in access to cancer care: a review of the Canadian literature. Cancer Causes Control, 22(3), 359-366. http://dx.doi.org/10.1007/s10552-010-9722-3

Merletti, F., Galassi, C., \& Spadea, T. (2011). The socioeconomic determinants of cancer. Environmental Health, 10(Suppl 1), 1-7. http://dx.doi.org/10.1186/1476-069X-10-S1-S7

Morimoto, L., Coalson, J., Mowat, F., \& O’Malley, C. (2010). Factors affecting receipt of chemotherapy in women with breast cancer. International Journal of Women's Health, 2, 107-122. http://dx.doi.org/10.2147/IJWH.S9125

Olver, I., Marine, F., \& Grogan, P. (2011). Disparities in Cancer Care in Australia and the Pacific. Oncologist, 16, 930-934. http://dx.doi.org/10.1634/theoncologist.2010-0404

Rosato, R., Sacerdote, C., Pagano, E., Du Cuonzo, D., Baldi, I., Bordon, R. ... Ciccone, G. (2009). Appropriateness of early breast cancer management in relation to patient and hospital characteristics: a population based study in Northern Italy. Breast Cancer Res Treat, 117, 349-356. http://dx.doi.org/10.1007/s10549-008-0252-6

Senior, K. (2009). Disparities in cancer survival and cancer care across Europe. Lancet Oncology, 10(3), 214-215. http://dx.doi.org/10.1016/S1470-2045(09)70058-0

Siminoff, L., \& Ross, L. (2005). Access and equity to cancer care in the USA: a review and assessment. Postgrad Med J, 81, 674-679. http://dx.doi.org/10.1136/pgmj.2005.032813

Zucca, A., Boyes, A., Newling, G., Hall, A., \& Girgis, A. (2011). Travelling all over the countryside: Travel-related burden and financial difficulties reported by cancer patients in New South Wales and Victoria. Aust. J. Rural Health, 19, 298-305. http://dx.doi.org/10.1111/j.1440-1584.2011.01232.x

\section{Copyrights}

Copyright for this article is retained by the author(s), with first publication rights granted to the journal.

This is an open-access article distributed under the terms and conditions of the Creative Commons Attribution license (http://creativecommons.org/licenses/by/3.0/). 